Proceedings

\title{
The Method of Spatial Suitability Assessment for Photovoltaic Development at the Municipality Scale ${ }^{\dagger}$
}

\author{
Łukasz Kolendo, Dorota Anna Krawczyk * and Andrzej Kobryń \\ Bialystok University of Technology, Faculty of Civil Engineering and Environmental Engineering, \\ Wiejska 45E, 15-351 Białystok, Poland \\ * Correspondence: d.krawczyk@pb.edu.pl \\ + Presented at Innovations-Sustainability-Modernity-Openness Conference (ISMO'19), Bialystok, Poland, \\ 22-23 May 2019.
}

Published: 31 July 2019

\begin{abstract}
The aim of the study was to develop a nationally universal method for estimating the solar resources and to assess, at the municipality scale, the suitability for photovoltaic development based on the implementation of GIS\&T (Geographic Information Science and Technology), multi-criteria analyses, and spatial data gathered from the National Geodetic and Cartographic Resources. The developed method is based on the use of digital topographic data and data gathered by means of modern remote sensing methods as a point cloud from airborne laser scanning. Based on studies in the literature, the formal and legal conditions applicable in Poland were discussed. The sets of constraints and factor criteria have been created as a base for evaluating the suitability of a chosen municipality for photovoltaic farms' emplacement. Weight calculations in a multi-criteria methodan AHP method (analytic hierarchy process)-were applied. In the multi-criteria analysis, 27 constraints and 13 factors were included. Undoubtedly, a utilitarian feature of the developed method is the calculation models allowing full automation of the process of spatial assessment of municipality territories for photovoltaic farms' development. Furthermore, calculation models can be easily adapted to some specific conditions that occur in the analyzed municipality territories. The results obtained confirm the significant usefulness of the implemented approach in the context of the spatial suitability assessment of photovoltaic development at the municipality scale.
\end{abstract}

Keywords: geographic information system and technology GIS\&T; multi-criteria analysis; photovoltaics; airborne laser scanning

\section{Introduction}

In recent years, in Poland, a systematic increase in the investments of installations based on the use of solar energy has been observed [1]. However, the usefulness of the country's areas in this sector is insufficiently recognized. Studies in the literature have the possibility of applying the conditions prevailing in Poland.

The main goal of this work was to develop a universal method for the spatial assessment of areas of the selected commune that is useful for photovoltaic technologies with a minimum capacity of 1 MW. As shown in previous studies [2-5], the location of these types of objects in a space (regardless of the geographical region of the world) requires consideration of many criteria with different characters. Within the scope of this work, a set of exclusion criteria (constraints) and a set of criteria of a soft nature (factors, parameters) were developed. The soft criteria were weighted using the chosen method of multi-criteria decision support-AHP (analytic hierarchy process) [6]. 


\section{Study Area}

Two areas located in municipalities in the Podlaskie Voivodship (northeastern Poland) were selected. They occupy a total area of 51,183 ha and constitute rural areas with a share of agricultural land (over $50 \%$ of the total area). There was no actual documentation related to spatial planning in the context of renewable energy resources' development. One of the analyzed areas is presented in Figure 1.

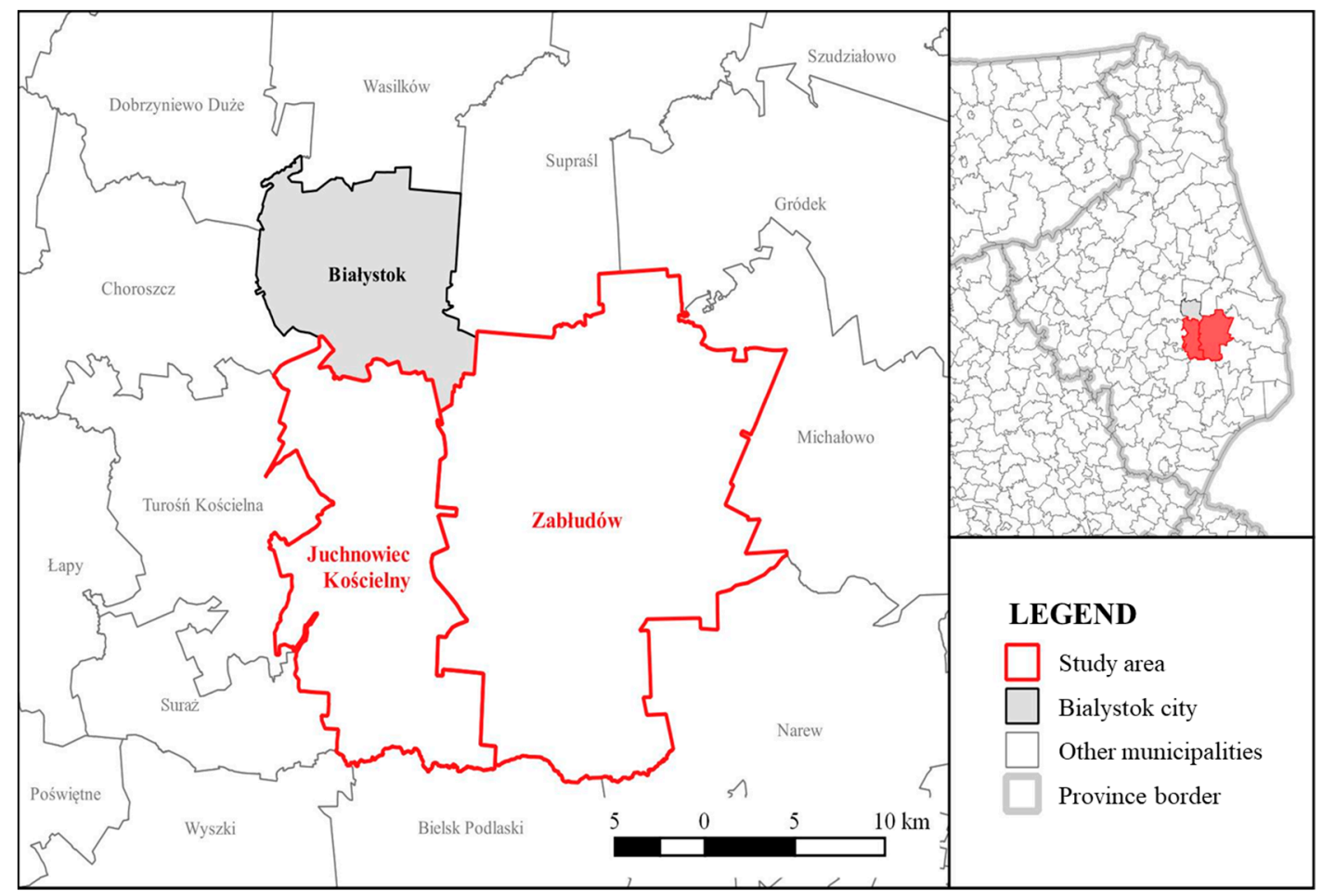

Figure 1. Location of the study area of Podlaskie province (northeastern Poland).

\section{Materials and Methods}

The research used GIS (Geographic Information Science), technology and spatial data collected using modern remote sensing technologies, including aerial laser scanning. As a result, computational models were developed to ease the process of determining areas unsuitable for the photovoltaic plants in the scale of the rural borough. Then, a spatial assessment in the scope of determining the suitability class for PV (photovoltaic) systems was done.

In the spatial assessment of the areas of the studied province, data collected in the Polish Geodetic and Cartographic Resources were widely used. The applied raster data included products derived from the processing of data from aerial laser scanning in the form of DTM (digital terrain model) and DSM (digital surface model) models, as well as a digital aerial orthophoto map. Moreover, a vector database of topographic objects, a flood hazard map, a map of soil conditions and land cover, and cadastral data were used.

We considered two basic categories of criteria: constraints and soft criteria (factors, parameters). In total, 27 types of constraints were taken into account. Subsequently, the pre-usable areas were divided in a segmentation process for their suitability for a 1-MW photovoltaic power plant using ten parameters focused on four basic groups: infrastructure, climate area, environmental-spatial, and social.

\section{Results}

As a result of the implementation of the set of constraints, we selected the area of the studied communes that can be found as pre-relevant for the installation of photovoltaic power plants with a minimum capacity of $1 \mathrm{MW}$ (Figure 2). 


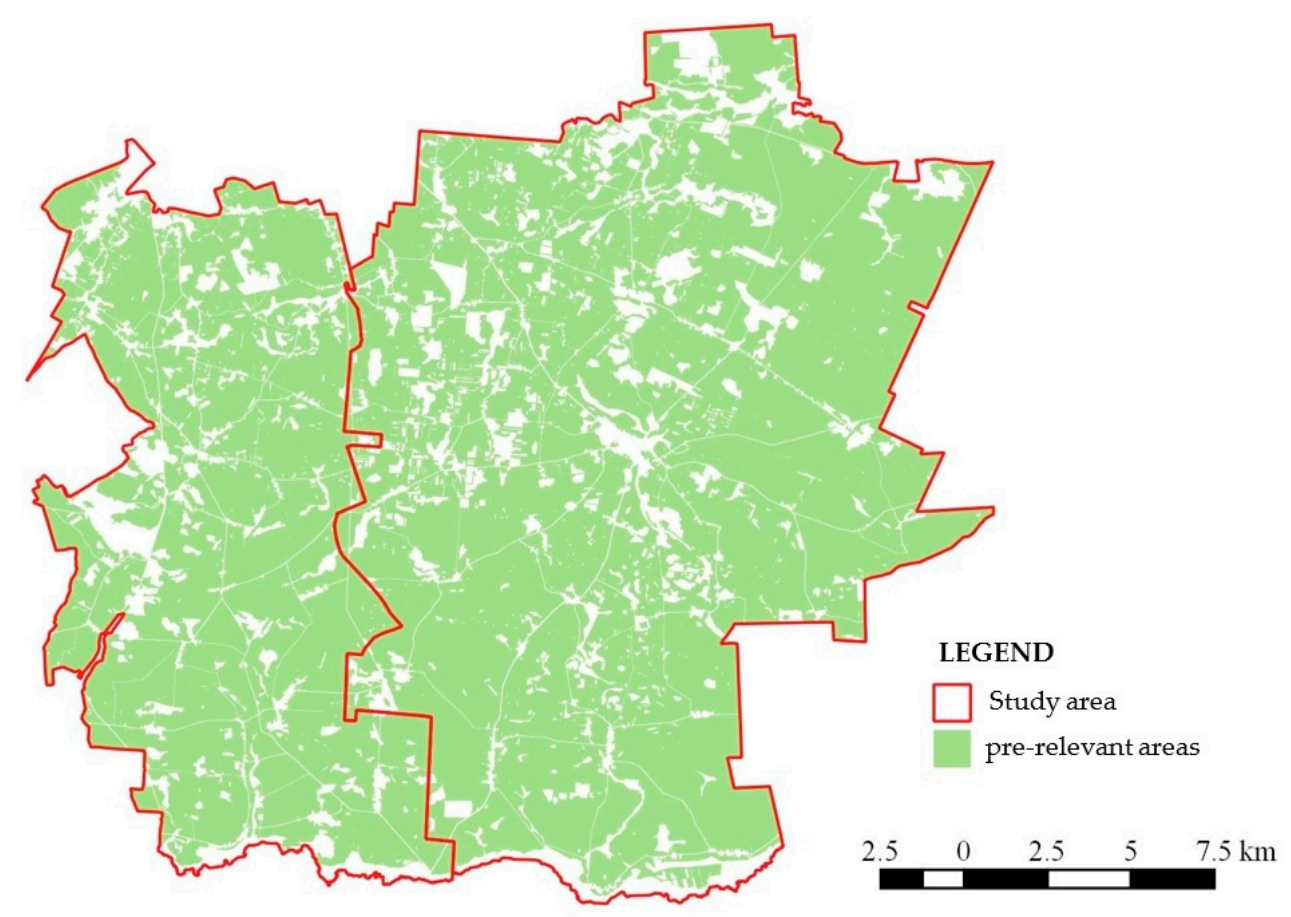

Figure 2. Spatial distribution of pre-relevant areas in the study area.

These areas constitute over $75 \%$ of the whole area of the analyzed communes. Among the excluded areas, the largest share was connected with the application of environmental criteria, including, among others, protected areas, covered by flood risk, or insufficient soil capacity. The selected areas have been divided into five suitability classes for photovoltaic plants' development. As a result of the detailed analysis, six variants of suitability maps were developed in the studied area. It is worth mentioning that in the applied sets of soft criteria, both the quantitative and spatial distribution of elementary cells representing particular classes of suitability were directly determined. The results obtained indicate that for all evaluation criteria used, the areas representing the first highest suitability class occupy only 2 to $13 \%$ of the studied area.

\section{Conclusions}

The conducted analysis allowed the areas with the best conditions for use as PV farms to be specified. It is also worth pointing out that the results are highly dependent on the weight functions taken for classes of usefulness. Research has shown that the adoption of different positions in the statistical weight process involves large changes in the spatial and quantitative dimensions of the distribution of suitability classes. Therefore, it is recommended that statistical weights should be established in the group of the widest possible body of experts in this field, taking into account the specific local conditions and national recommendations. However, developed computational models provide versatile and flexible tools and demonstrate a high application value for the planning of solar investments in Polish municipalities.

Acknowledgments: This work was supported by the resources of statutory work financed by the Ministry of Science and Higher Education of Poland References. This publication was supported by VIPSKILLS Project 20161-PL01-KA203-026152 Erasmus +.

Author Contributions: All authors conceived and designed the analysis, as well as analyzed results; Ł.K. performed the calculations, Ł.K. and D.A.K. wrote the paper.

Conflicts of Interest: The authors declare no conflict of interest. 


\section{References}

1. Energy Regulatory Office. Available online: https:/www.ure.gov.pl/pl/urzad/informacjeogolne/aktualnosci/3232,Interaktywna-mapa-odnawialnych-zrodel-energii-juz-na-stronie-URE.html (accessed on 25 December 2018).

2. Aydin, N.Y.; Kentel, E.; Duzgun, H.S. GIS-based site selection methodology for hybrid renewable energy systems: A case study from western Turkey. Energy Convers. Manag. 2013, 70, 90-106, doi:10.1016/j.enconman.2013.02.004.

3. Sánchez-Lozano, J.M.; Antunes, C.H.; García-Cascales, M.S.; Dias, L.C. GIS-based photovoltaic solar farms site selection using ELECTRE-TRI: Evaluating the case for Torre Pacheco, Murcia, Southeast of Spain. Renew. Energy 2014, 66, 478-494, doi:10.1016/j.renene.2013.12.038.

4. Sabo, M.L.; Mariun, N.; Hizam, H.; Radzi, M.; Zakaria, A. Spatial energy predictions from large-scale photovoltaic power plants located in optimal sites and connected to a smart grid in Peninsular Malaysia. Renew. Sustain. Energy Rev. 2016, 66, 79-94, doi:10.1016/j.rser.2016.07.045.

5. Zoghi, M.; Ehsani, H.E.; Sadat, M.; Amiri, M.; Karimi, S. Optimization solar site selection by fuzzy logic model and weighted linear combination method in arid and semi-arid region: A case study Isfahan-Iran. Renew. Sustain. Energy Rev. 2017, 68, 986-996, doi:10.1016/j.rser.2015.07.014.

6. Saaty, T. The Analytic Hierarchy Process: Planning. Priority Setting. Resource Allocation. McGraw-Hill: New York, NY, USA, 1980.

(C) 2019 by the authors. Licensee MDPI, Basel, Switzerland. This article is an open access article distributed under the terms and conditions of the Creative Commons Attribution (CC BY) license (http://creativecommons.org/licenses/by/4.0/). 